\title{
Ibrutinib: \\ From Molecule to Medicine
}

\author{
Orhan AYYILDIZ ${ }^{1}$, Fatih DEMIRKAN², Hakan GOKER ${ }^{3}$, Ibrahim C. HAZNEDAROGLU ${ }^{3}$, \\ Osman ILHAN $^{4}$, Leyla G. KAYNAR ${ }^{5}$, Evren OZDEMIR ${ }^{6}$, Guray SAYDAM ${ }^{7}$, Nilgun SAYINALP ${ }^{3}$, \\ Fahri SAHIN ${ }^{7}$, Mehmet TURGUT ${ }^{8}$, Ali UNAL ${ }^{5}$, Filiz VURAL ${ }^{7}$
}

${ }^{1}$ Dicle University Faculty of Medicine, Department of Internal Medicine, Diyarbakir

${ }^{2}$ Dokuz Eylul University Faculty of Medicine, Department of Hematology, Izmir

${ }^{3}$ Hacettepe University Faculty of Medicine, Department of Hematology, Ankara

${ }^{4}$ Ankara University Faculty of Medicine, Ibn-i Sina Hospital, Department of Internal Medicine, Ankara

${ }^{5}$ Erciyes University Faculty of Medicine, Department of Hematology, Kayseri

${ }^{6}$ Hacettepe University Faculty of Medicine, Department of Oncology, Ankara

${ }^{7}$ Ege University Faculty of Medicine, Department of Hematology, Izmir

${ }^{8}$ Ondokuz Mayis University Faculty of Medicine, Department of Hematology, Samsun, TURKEY

\begin{abstract}
Bruton's tyrosine kinase (BTK) inhibitor lbrutinib (PCl-32765) is a novel targeted-therapeutic agent modulating BCR, which serves as a covalent irreversible inhibitor of BTK. Ibrutinib significantly alters the composition of the tumor microenvironment in CLL, affecting soluble as well as cellular molecular elements without myelosupression. Ibrutinib is clinically developed as an orally administered anti-cancer agent with lead indications in relapse/refractory and in treatment-naïve patients with B-cell malignancies as a single agent. The clinical activities of Ibrutinib as a drug were shown in the B-cell malignancies, especially in patients with CLL, mantle cell lymphoma (MCL), and Waldenstrom's macroglobulinemia (WM). Ibrutinib has generated the most extensive results so far in patients with CLL, predominately refractory or relapsed CLL where durable disease control as well as improved progression-free survival (PFS) and overall survival (OS) has been observed. The aim of this review is to outline the pharmacophysiological basis of Ibrutinib treatment as well as the current clinical experience based on the trials. The treatment algorithms of B-lymphoproliferative diseases will continue to be revised to a more personalized approach to treat with improved efficacy devoid of unnecessary toxicity.
\end{abstract}

Keywords: Ibrutinib, CLL, BCR, BTK

ÖZET

\section{İbrutinib: Molekülden İlaca}

Bruton tirozin kinaz (BTK) inhibitörü Ibrutinib (PCl-32765), BTK üzerine irreversibl kovalan bağlanarak BCR aktivitesini yönlendiren yeni bir hedeflenmiş tedavi ajanıdır. Ibrutinib, kronik enfositik lösemi (KLL)'de tümör mikroçevresini hücresel moleküler elemanlar üzerinden myelosupresyona yol açmaksızın etkiler. Oral ibrutinib relaps/refrakter veya yeni tanı B-hücre malinitelerinde değişik klinik çalışmalarda test edilmektedir. KLL, mantle hücreli lenfoma (MCL) ve Waldenstrom makroglobulinemi (WM) hastalıklarında ibrutinib klinik çalısmaları devam etmektedir. Ibrutinib, klinik deneyimi özellikle relaps/refrakter KLL alanında progresyonsuz yaşam süresi (PFS) ve genel yaşam süresi (OS) iyileşmeleri ile birlikte hastalık kontrolü sağlamak amaçı şekillenmiştir. Bu yazının amacı, ibrutinib tedavisinin farmakofizyolojik temellerine değinmek ve konu ile ilgili klinik çalışma deneyimlerini aktarmaktır. B-lenfoproliferatif hastalıkların tedavi şemaları, etkinliği artırmak ve hastaları gereksiz toksisiteden korumak üzerine odaklı olarak güncellenmeye devam edecektir.

Anahtar Kelimeler: İbrutinib, KLL, BCR, BTK 


\section{INTRODUCTION}

Pathobiological expression of the B-cell receptor (BCR) signaling can cause disease progression in the malignant B-cell neoplastic diseases. ${ }^{1}$ Bruton's tyrosine kinase (BTK) has a pivotal role in the BCR signaling. Normal B lymphocytes receive signals from $\mathrm{BCR}$ that are triggered by binding of the $\mathrm{BCR}$ to an external antigen. Tonic signaling through the BCR provides growth and signals to chronic lymphocytic leukemia (CLL) cells, and plays an important role in the pathogenesis and progression of the disease. ${ }^{2}$ BTK is a cytoplasmic tyrosine kinase transmitting neoplastic signals from the BCR and tissue homing receptors. ${ }^{3}$ BTK inhibitor Ibrutinib (PCI-32765) is a novel targeted-therapeutic agent which serves as a covalent irreversible inhibitor of BTK. ${ }^{4}$ The clinical activities of Ibrutinib as a drug were shown in the Bcell malignancies ${ }^{5,6}$, especially in patients with CLL, mantle cell lymphoma (MCL), and Waldenstrom's macroglobulinemia (WM). ${ }^{3,7}$ Ibrutinib has generated the most extensive results so far in patients with CLL, predominately refractory or relapsed CLL where durable disease control as well as improved PFS and OS has been observed. ${ }^{8-14}$ BTK is a critical kinase for CLL development and expansion and thus an important target of ibrutinib. ${ }^{15}$ Ibrutinib causes an early redistribution of tissue-resident malignant B-cells, including CLL cells, into the blood, with rapid resolution of enlarged lymph nodes, along with a surge in lymphocytosis. After weeks to months of continuous ibrutinib therapy, the growth- and survival-inhibitory activities of ibrutinib result in the normalization of lymphocyte counts and remissions in a majority of patients with CLL. ${ }^{16}$

Ibrutinib can induce the redistribution of malignant B cells from tissue sites into the peripheral blood together with the rapid resolution of enlarged neoplastic lymph nodes. ${ }^{3}$ Ibrutinib significantly alters the composition of the tumor microenvironment in CLL, affecting soluble as well as cellular molecular elements. ${ }^{17}$ Ibrutinib does not cause myelosuppression. ${ }^{4}$ With continuous ibrutinib therapy, growth- and survival-inhibitory activities of ibrutinib could result in the normalization of lymphocyte counts and remissions in the patients with B-cell neoplastic diseases. Ibrutinib is the first BTK inhibitor that is being used and approved in the clinical practice with the most mature clinical data. ${ }^{18}$ The drug was designed as a selective and irreversible inhibitor of the BTK protein, and it inhibits signal transduction from the BCR and blocks activation of B cells. ${ }^{19}$ The aim of this review is to outline this kind of BTK inhibitor therapy as well as its pathophysiological ways.

\section{Pharmacobiological Basis of Ibrutinib}

BCR is essential for normal B-cell development and maturation. On the other hand, BCR signaling is implicated as a pivotal pathway in tumorigenesis. ${ }^{20} \mathrm{BTK}$ signaling pathways in the cellular microenvironment is depicted in Figure 1.

CLL cells in the lymph node and bone marrow microenvironments demonstrate higher levels of BCR and NF- $\kappa \mathrm{B}$ signaling. ${ }^{21}$ Mechanisms of BCR activation may include chronic antigenic drive by microbial or viral antigens, auto-stimulation of B-cells by selfantigens, and activating mutations in the intracellular components of the BCR pathway. ${ }^{20}$ B-lymphocytes have critical functions in the immune response, including antigen presentation, antibody production, and cytokine release. BCR, which is activated by binding to antigen, can induce receptor aggregation together with the activation of multiple tyrosine kinases and downstream signaling pathways. ${ }^{20}$ The activating mutations in signal transduction components of the BCR pathway have been identified In B-cell malignancies. Likewise B-lymphoproliferative diseases are sensitive to kinase inhibitors that disrupt BCR signaling. Thus, targeted therapy through inhibition of BCR signaling is emerging as a new treatment paradigm for many B-cell neoplastic disorders. ${ }^{20}$ Given the central role of BTK in BCR signaling and the importance of BCR signaling in lymphoproliferative diseases, the inhibition of BTK by ibrutinib could be an effective therapeutic strategy in B-cell malignancies.

BTK is a Tec family cytoplasmic tyrosine kinase that is a key component of BCR signaling pathway and is critical for normal B cell development, differentiation, proliferation and survival. BTK is a 659-aminoacid protein that contains five signaling domains and has diverse partner molecules. ${ }^{22}$ BTK transmits, diversifies, and amplifies signals from a wide variety of surface molecules that cells use to communicate with their microenvironment. BTK is a central signaling node mediating the nourishing and protective effects of the tumor microenvironment. ${ }^{23} \mathrm{BTK}$ is also essential for the homing of MCL cells into lymphoid tissues, and its inhibition results in an egress of ma- 


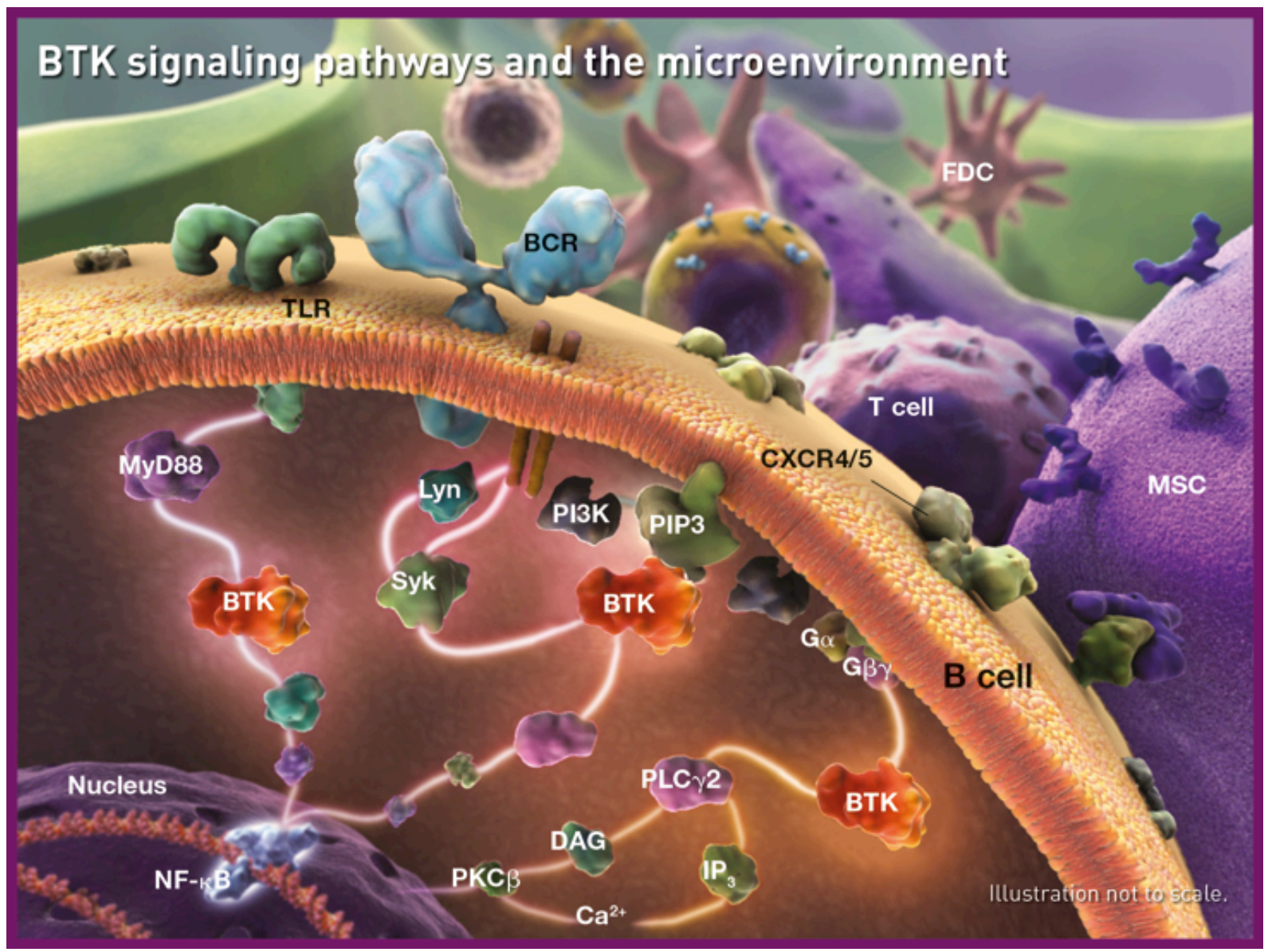

Figure 1. Bruton's tyrosine kinase (BTK) has a pivotal role in the BCR signaling. BTK is a cytoplasmic tyrosine kinase transmitting neoplastic signals from the BCR and tissue homing receptors

lignant cells into peripheral blood. ${ }^{24}$ The absence of BTK predominantly affects B cell function. In the absence of BTK, BCR signaling is insufficient to induce late transitional $\mathrm{B}$ cells to differentiate into mature peripheral B cells. BCR signaling pathway genes are constitutively increased in B cell tumors, manageable via the therapeutics targeting BTK. ${ }^{19,22}$ BTK inhibition using the BTK inhibitor ibrutinib decreased DNA synthesis and prosurvival signal from stromal cells and cytokines.

Ibrutinib can effectively inhibit neoplastic pathways that promote tumor cell activation and proliferation. The anti-neoplastic effect of Ibrutinib is depicted in Figure 2. Herman and coworkers ${ }^{23}$ evaluated the in vivo effects of ibrutinib, the BTK inhibitor on tumor cell activation and proliferation in the peripheral blood, lymph nodes, and bone marrow of the patients with CLL. ${ }^{23}$ They detected a rapid and sustained down-regulation of BCR and NF-kappaB signaling in CLL cells from both the peripheral blood and tissue compartments during ibrutinib treatment. In their study, ibrutinib significantly decreased tumor proliferation and expression of surface activation markers CD69 and CD86 independent of the well-known CLL prognostic factors such as IGHV mutational status, chromosome $17 \mathrm{p}$ deletion, or prior chemotherapy. ${ }^{23}$

\section{Anti-neoplastic Molecular Activities of Ibrutinib}

Ibrutinib inhibits both BCR and NF-kB signaling in lymph node and bone marrow resident CLL cells. ${ }^{25} \mathrm{In}$ a number of B-cell malignancies such as diffuse large B-cell lymphomas (DLBCL), activating mutations in signal transduction components of the BCR pathway have been identified; prominent examples are activated B-cell-like that carry mutations in CD79B and display chronic active $\mathrm{BCR}$ signaling resulting in constitutive activation of the NF-kappa B pathway. ${ }^{20}$ The effects of Ibrutinib on BCR and NF-kB are depicted in Figure 3.

Ibrutinib inhibits activation and proliferation of CLL 


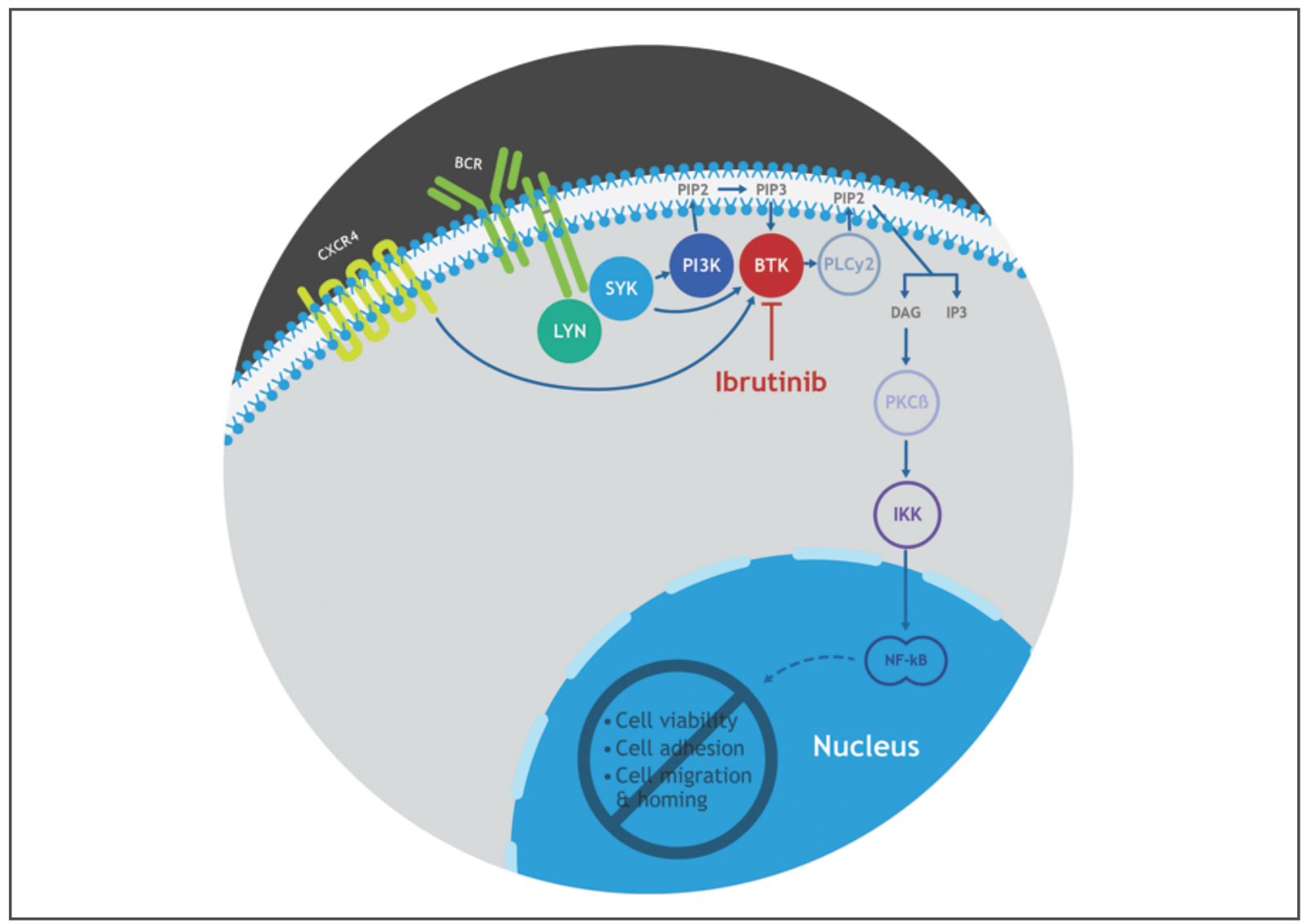

Figure 2. Anti-neoplastic effects of Ibrutinib via acting on BTK in the BCR signaling, which is central in the B-lymphoproliferative diseases

cells in vivo. On-target effects of BTK inhibition in tissue-resident CLL cells were shown. Blocking cell proliferation via inhibition of BTK-mediated signaling may contribute to clinical responses in ibrutinibtreated patients. ${ }^{26}$ Binding site between Ibrutinib and BTK is well described (Figure 4).

The chemokines in tumor cell-microenvironment interactions represent a target for treatment of CLL. ${ }^{27}$ Chemokine receptors expressed on CLL cells regulate the migration of the leukemia cells within the bone marrow, lymphoid organs in collaboration with chemokines. Furthermore, chemokines produced in distinct tissue microenvironments sustain migration of mature lymphocytes in lymphoglandula. Chemokines form a pro-survival circuitry by regulating leukocyte trafficking, maintaining extended lymphocyte survival. ${ }^{27} \mathrm{~A}$ potentially dangerous subpopulation of CLL cells equipped to migrate to tissue and receive a proliferative stimulus. ${ }^{28}$ Ibrutinib inhibits the migration of CLL cells in chemokine gradients. ${ }^{29}$ Chemokine signaling is blocked by ibrutinib so that the neoplastic migration of the B-cells is impaired
(Figure 5).

Treatment with Bruton's tyrosine kinase inhibitor could enhance Fas-mediated apoptosis in lymphoproliferative diseases. ${ }^{30}$ The reduction of tissue disease burden by ibrutinib is due more to CLL cell death and less to egress from nodal compartments. ${ }^{31}$ Moreover, rapid and sustained reduction of the cellular activation and tumor proliferation has been shown to be achieved by ibrutinib in all of the anatomic compartments related to the neoplastic development of CLL disease course. ${ }^{25}$ Ibrutinib may alter the composition of the bone marrow microenvironment. ${ }^{29}$ ibrutinib leads to a transient increase in circulating CLL cells consistent with the efflux of activated cells from the tissue compartments leading to the reduction in lymphadenopathy. ${ }^{13}$ Ibrutinib-induced early-onset lymphocytosis $^{32}$ develops within hours due to the release of previously activated resident cells from the tissue microenvironments. The rapid onset of the lymphocytosis and the dramatic defect in the adhesion process suggested that ibrutinib directly interferes with an intracellular signaling network required for cell 


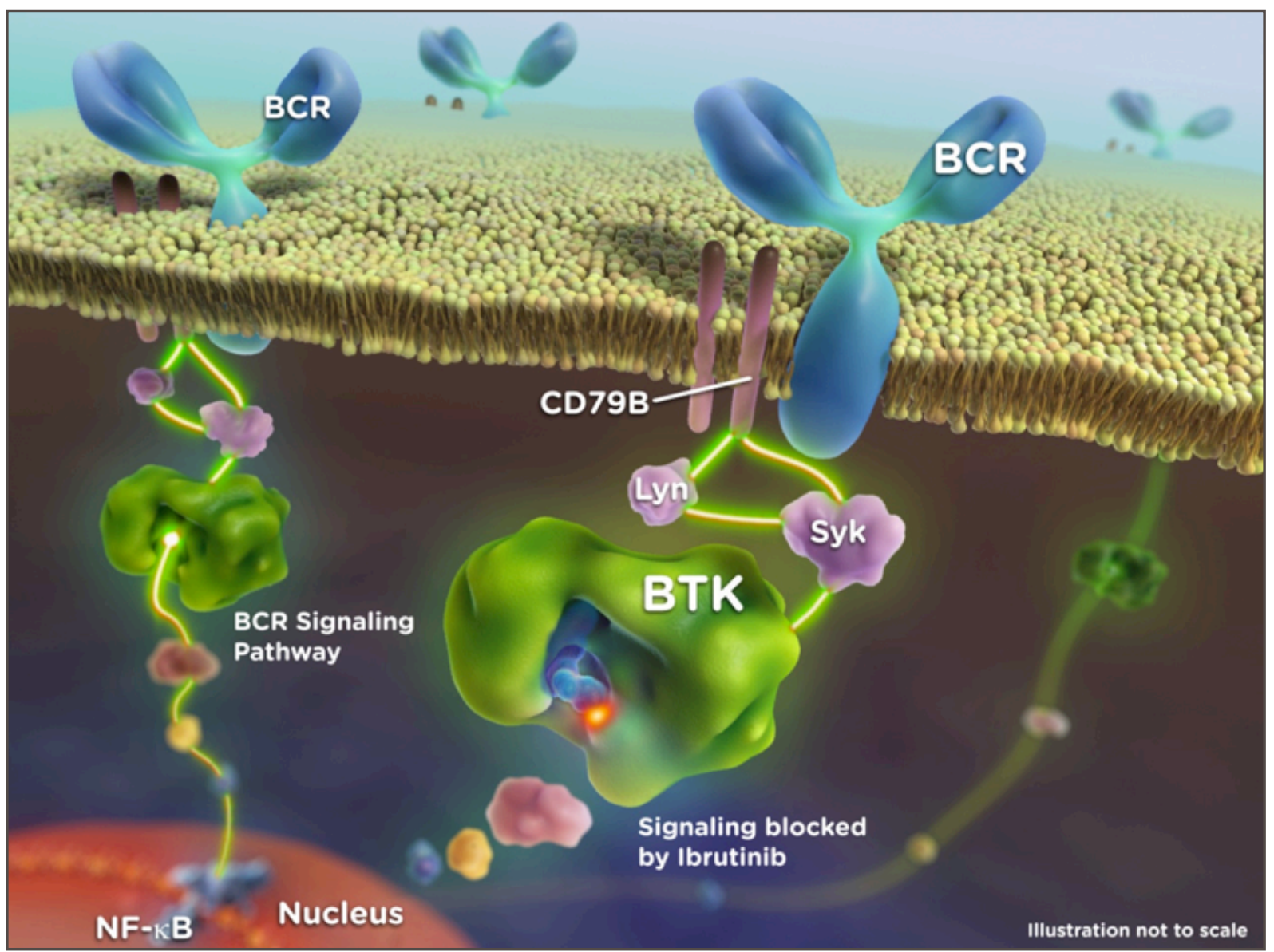

Figure 3. Anti-neoplastic effects of Ibrutinib via acting on on BCR signaling and NF-kappaB in relation to the Bruton's tyrosine kinase (BTK) inhibition and CD79b

adhesion. ${ }^{33}$ Upon initiation of treatment with ibrutinib, the transient phase of increase in lymphocyte counts (ie, $\geq 50 \%$ increase from baseline and above absolute count $5.000 \mu \mathrm{L}$ ) often associated with reduction of lymphadenopathy was observed in most subjects with relapsed/refractory CLL. This effect has also been observed in some subjects with relapsed/ refractory MCL treated with ibrutinib monotherapy. This observed transient lymphocytosis is usually not associated with an adverse event and should not be considered progressive disease in the absence of other clinical findings. Lymphocytosis in subjects with CLL on ibrutinib therapy typically occurs during the first few weeks of ibrutinib therapy and typically resolves within weeks to months, while on treatment. The kinetics and degree of the treatment-induced lymphocytosis could be variable. CLL patients with a high baseline absolute lymphocyte count, the relative increase may be more indolent. No adverse events were attributed to the Ibrutinib-induced early-onset lymphocytosis in clinical trials..$^{34}$ No cases of ibrutinib-induced leukostasis were reported in subjects with CLL/SLL receiving ibrutinib, although subjects with a high number of circulating malignant cells $(>400,000 \mathrm{k} / \mathrm{uL}$ ) should be closely monitored. In subjects with CLL receiving ibrutinib in combination with chemoimmunotherapy or immunotherapy, lymphocytosis appeared to occur in lower incidence and at lesser magnitude.

\section{Clinical Trials of Ibrutinib in CLL and other B- Malignant Diseases}

The diagnosis of early-stage and the treatment of advanced-stage CLL may sometimes be challenging. ${ }^{35,36}$ Ibrutinib is clinically developed as an orally administered anti-cancer agent with lead indications in relapse/refractory and in treatment-naïve patients with B-cell malignancies as a single agent. ${ }^{37}$ In addition, combination studies with chemoimmunotherapy and immunotherapy have also been performed. ${ }^{38-44}$ The 


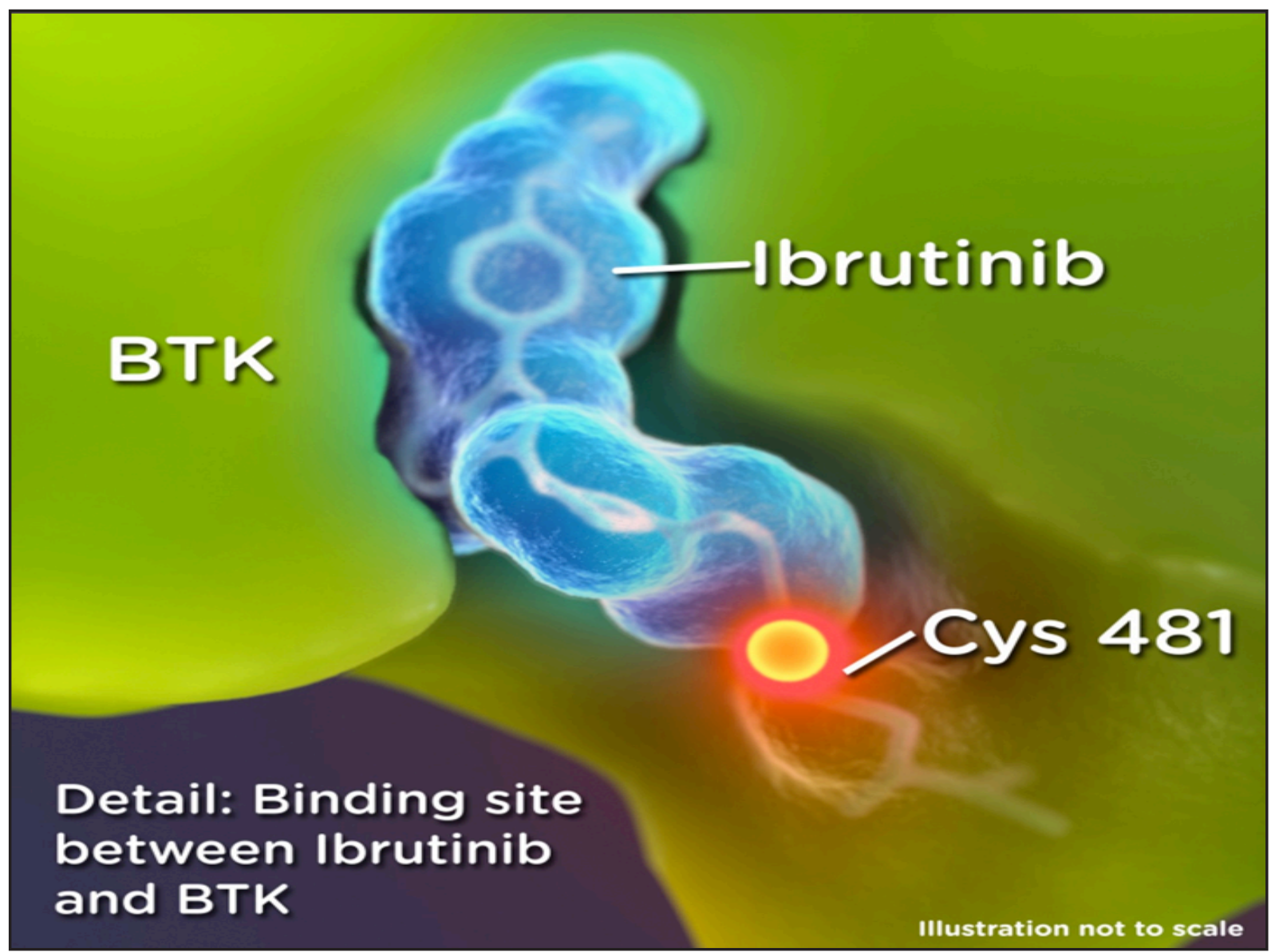

Figure 4. The binding site between Ibrutinib and Bruton's tyrosine kinase (BTK). Ibrutinib (PCl-32765), a potent inhibitor of BTK induces impressive responses in B-cell malignancies through a covalent bond with cysteine-481 in the active site of $\mathrm{BTK}(\mathrm{TH} / \mathrm{SH} 1$ domain) and inhibits BTK phosphorylation on Tyr223.14

Phase $1 \mathrm{~b} / 2$, multicenter, open-label, parallel-group safety study of the BTK inhibitor PCI-32765 (ibrutinib) in combination with chemotherapy in subjects with CLL disclosed the safety of the drug. ${ }^{45}$ That was a multicenter Phase 1b/2 study in patients with CLL receiving concurrent conventional chemoimmunotherapy. The patients were enrolled into one of two cohorts defined by the chemotherapy regimen selected by the investigator; the FCR cohort (fludarabine, cyclophosphamide and rituximab) or the BR (bendamustin and rituximab) cohort. CLL patients receive up to 6 cycles of chemoimmunotherapy with a continuous fixed ibrutinib dose of $420 \mathrm{mg} / \mathrm{day}$; ibrutinib dosing continued past 6 cycles until disease progression or other reason for discontinuation. The objectives of the study included studying the safety profile of ibrutinib in combination with these therapeutic agents, and an assessment of the efficacy as measured by response rate, time to response, and duration of response. The study enrolled 33 subjects. Thirty sub- jects were enrolled in the BR cohort and 3 subjects in the FCR cohort. Enrollment into the FCR cohort was difficult due to shifts in clinical practice, leading to few fludarabine-naive subjects in the relapsed setting. Enrollment in the BR cohort was deemed adequate for assessing the trial's objectives. Twenty-one (70\%) subjects in the BR Cohort and $3(100 \%)$ subjects in the FCR Cohort who were still receiving ibrutinib monotherapy treatment after completion of $\mathrm{BR}$ or FCR rolled over to continue treatment with ibrutinib. At the study closure, the most frequently reported treatment-emergent, adverse events among the 30 BR subjects were diarrhea (70\%), nausea $(66.7 \%)$, fatigue $(46.7 \%)$, neutropenia (40\%) and upper respiratory tract infection (36.7\%). The most frequently reported treatment-emergent adverse events of Grade 3 or higher in severity were neutropenia $(40.0 \%)$, macula-papular rash and fatigue (10.0\% each), and thrombocytopenia, febrile neutropenia, and cellulitis (6.7\% each). During the study conduct, 9 of the BR 


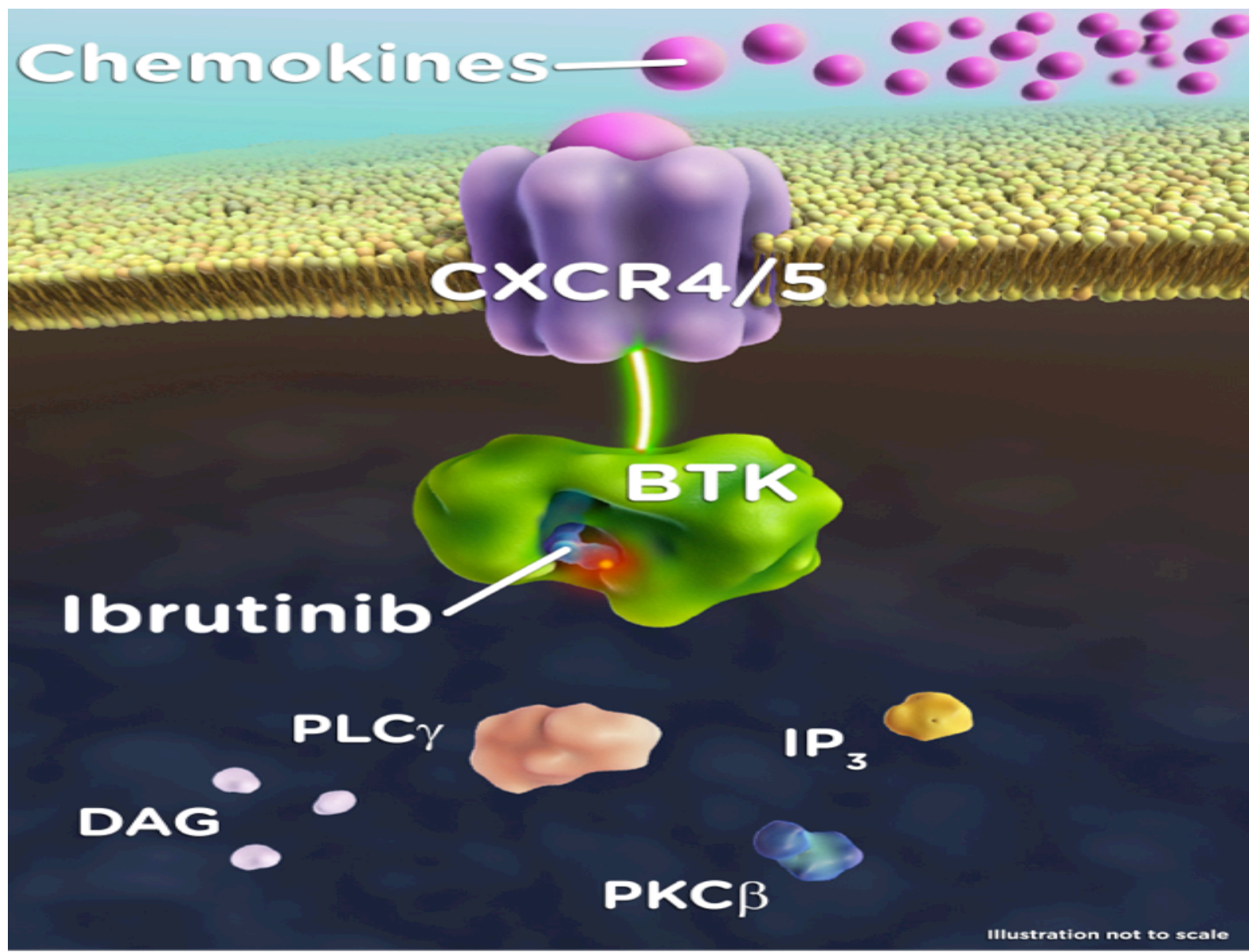

Figure 5. The binding of Ibrutinib to Bruton's tyrosine kinase (BTK) can block chemokine signaling in the malignant B cell

subjects $(30 \%)$ discontinued the study treatment, 5 (17\%) subjects proceeded to stem cell transplant and $4(13 \%)$ subjects discontinued due to PD. With a median follow-up of 8.1 months (range: 2.7 - 11.3) four subjects had achieved a complete remission (CR) and 24 subjects had achieved a partial response (PR), for an overall response rate of $93 \% .^{45}$

The safety and activity of ibrutinib, the orally administered covalent inhibitor of BTK, was also studies in treatment-naive patients aged 65 years and older with CLL.13 In this study, the patients with CLL had received 28 day cycles of once-daily ibrutinib $420 \mathrm{mg}$ or ibrutinib $840 \mathrm{mg}$. The $840 \mathrm{mg}$ dose of ibrutinib was discontinued after enrolment had begun because a comparable activity of the doses was shown. The primary endpoint was the safety of the dose-fixed regimen in terms of frequency and severity of adverse events for all patients who received treatment. The median age was 71 years and $23(74 \%)$ patients were older than 70 years. Median follow-up for all patients was 22.1 months. Twenty-seven patients were treated with ibrutinib $420 \mathrm{mg}$ and four were treated with ibrutinib $840 \mathrm{mg}$. Median treatment duration was 21.0 months. The relative dose intensity (percentage of expected dose received) was $98.9 \% \cdot{ }^{13}$ Based on the results of this study, $22(71 \%)$ of 31 patients achieved an objective response (CR and PR), with four (13\%) achieving a CR. Four patients (13\%) had a PR with lymphocytosis, and three patients $(10 \%)$ had stable disease; median follow-up for these seven patients was 20.3 months, as compared with 22.1 months for the 22 patients who achieved PR or CR. Of the 22 patients who achieved a CR or PR, the initial responses were ten PR with lymphocytosis, and 12 true partial responses. For the ten patients who initially responded with PR with lymphocytosis, the median time to true PR or CR was 7.3 months..$^{13}$ Thus, ibrutinib is well tolerated and effective in the previously untreated population of elderly patients with CLL. Blocking cell proliferation via inhibition of BTK-me- 
diated signaling may contribute to clinical responses in ibrutinib-treated patients with CLL. ${ }^{26}$

One unresolved question about ibrutinib in CLL is whether an improvement in outcome is associated with a rapid achievement of response. ${ }^{13}$ The low degree of myelosuppression associated with ibrutinib in CLL and the acceptable non-haematological toxicities make it possible to combine ibrutinib with other agents, both cytotoxic drugs and non-cytotoxic therapies, including B-cell-depleting monoclonal antibodies such as rituximab. ${ }^{40}$ Even though in vitro data indicate that ibrutinib antagonizes rituximab-dependent NK cell-mediated cytotoxicity the combination has achieved a high frequency of objective responses together with early resolution of lymphocytosis compared with single-agent ibrutinib treatment. ${ }^{41,42,45}$, 46 Future combination therapies with established CLL treatment modalities (monoclonal antibodies, chemoimmunotherapy) will likely achieve the goal of higher CR in CLL. The risk-benefit ratio may favor combination over single agent ibrutinib therapy in CLL subgroups. ${ }^{22}$ Elderly patients (over 70 years) may not tolerate chemoimmunotherapy in comparison to the younger patients with CLL. Thus, ibrutinib monotherapy or combinations with antibodies are more appropriate in the aged population and/or poor performance with co-morbidities. More intensive chemoimmunotherapy-based combinations may be convenient in younger high-risk patients with B-cell malignancies. The debulking of the neoplastic disease with ibrutinib followed by cellular therapies could be the most important clinical strategy. ${ }^{22}$

Ibrutinib is active in B-lymphomas. ${ }^{22,47,48}$ The efficacy, lack of toxicity and oral administration of ibrutinib will ensure the adoption of the drug for the management of a wide range of B-cell malignancies. ${ }^{37}$ BTK signaling plays a critical role in MCL cell survival, and the targeting of BTK could represent a promising therapeutic modality for aggressive lymphoma. ${ }^{49,50}$ Thus, MCL, the clinically aggressive and incurable B-cell malignancy, may respond to ibrutinib therapy. ${ }^{1,3,22,24,44,49}$ The blockade of BTK activity by ibrutinib could attenuate BCR signaling and induces cell death in a wide variety of B-lymphoproliferative diseases. A moderate to strong BTK expression in MCL cases in comparison to benign lymphoid tissues has been shown. Treatment of those MCL cell lines with Ibrutinib decreased the viability of neoplastic cells and induced apoptosis. ${ }^{49}$ In a non-randomized
Phase II study, 115 patients with MCL were enrolled and classified as either having received treatment with bortezomib ( $\geq 2$ cycles) or not having received such treatment $(<2$ complete cycles or no prior bortezomib therapy).51 In this study, the estimated median follow-up was 15.3 months (range, 1.9 to 22.3). The response rate for all patients was $68 \%$, with $47 \%$ of patients having a PR and $21 \%$ having a CR. Of 43 patients with lymph nodes that were at least $5 \mathrm{~cm}$ in diameter, 27 (63\%) had a response to treatment. Response rates were similar in bortezomib naive and bortezomib exposed patients. Furthermore, 17 of 27 patients $(63 \%)$ previously treated with lenalidomide had a response to ibrutinib. The overall response rate and the complete response rate also improved over time with continued therapy. The most common nonhematologic adverse events occurring in more than $20 \%$ of patients were diarrhea (in 50\% of patients), fatigue (in 41\%), nausea (in 31\%), peripheral edema (in 28\%), dyspnea (in 27\%), constipation (in 25\%), upper respiratory tract infection (in 23\%), pneumonia (in $6 \%$ of patients), vomiting (in 23\%), and decreased appetite (in 21\%). Grade 3 and 4 hematologic adverse events included neutropenia (in 16\% of patients), thrombocytopenia (in 11\%), and anemia (in $10 \%)$. Grade 3 bleeding events occurred in five patients, with no grade 4 or 5 hemorrhagic events. With respect to efficacy, a response rate of $68 \%$ and a $\mathrm{CR}$ rate of $21 \%$ (CR rate of $37 \%$ among the 51 patients who had been receiving treatment the longest) are high response rates for a single agent in this patient population. Previously, such a high rate of CR in this population with substantial previous treatment has been achieved only with intensive chemotherapy regimens. ${ }^{51}$ Thus, ibrutinib shows durable single-agent efficacy in relapsed or refractory MCL.

Phase III trials are underway worldwide to evaluate ibrutinib in the treatment of patients with CLL/SLL, DLBCL and MCL. Moreover, ibrutinib is in phase II development ${ }^{52}$ for use in Waldenstrom's macroglobulinemia (WM), follicular lymphoma (FL) and multiple myeloma (MM)38. Ibrutinib significantly inhibited Hairy cell leukemia (HCL) proliferation and cell cycle progression. ${ }^{53}$ A Phase I study of Ibrutinib in relapsed B-cell malignancies suggested activity in a number of different lymphomas. ${ }^{54}$ This study enrolled 56 patients with various histologies, including DLBCL, MCL, FL, CLL, marginal zone lymphoma (MZL), and Waldenström'smacroglobulinemia (WM). Ibrutinib was well tolerated and of the $50 \mathrm{pa}-$ 
tients evaluable for response, $30(60 \%)$ had an objective response with $8(16 \%)$ complete responses (CR)55. Specifically, responses were seen in 2 of 7 patients with DLBCL, 7 of 9 patients with MCL, 6 of 16 patients with FL, 11 of 16 patients with CLL, 1 of 4 patients with MZL, and 3 of 4 patients with WM. Median progression-free survival was 13.6 months in the study. Similar clinical trials in B-cell neoplastic diseases are underway. ${ }^{54-58}$

In a very recent clinical trial ${ }^{59}$, Byrd and coworkers compared the efficacy and safety of ibrutinib versus ofatumumab in patients with previously treated (relapsed or refractory) CLL or small lymphocytic leukemia (SLL) in a phase 3, open-label multicenter study ${ }^{59}$ The patients were randomly assigned on a 1:1 basis to receive either oral ibrutinib or intravenous Ofatumumab. They received oral ibrutinib $420 \mathrm{mg}$ once daily until disease progression or the occurrence of unacceptable toxicity. Intravenous ofatumumab was given over a 24-week period. The initial dose at Week 1 was $300 \mathrm{mg}$, followed by a dose of $2000 \mathrm{mg}$ weekly for 7 weeks and then every 4 weeks for 16 weeks, consistent with local labeling. The patients were stratified according to resistance to purine analogue chemoimmunotherapy (defined as no response or a relapse within 12 months after last dose of a purine analogue) and the presence or absence of the 17p13.1 deletion. Three hundred and ninety-one patients were enrolled and received either oral ibrutinib $(n=195)$ or intravenous ofatumumab $(n=196)$. The Primary End point was Progression-free survival (PFS), as assessed by the International Workshop on Chronic Lymphocytic Leukemia (IWCLL) criteria. The majority of patients had CLL (> 95\%) and advanced-stage disease; across the treatment groups $31 \%$ had the $17 \mathrm{p} 13.1$ deletion and $32 \%$ the $11 \mathrm{q} 22.3$ deletion; more patients in the ibrutinib group than the ofatumumab group ( $64 \%$ vs $52 \%$; $p=0.04$ ) had bulky disease $(\geq 5 \mathrm{~cm})$. Patients in the ibrutinib group had undergone a median of 3 prior treatments and patients in the ofatumumab group had undergone a median of 2 prior treatments; most patients had received prior treatment with purine analogues, alkylating agents, and anti-CD20 agents. Median follow-up was 9.4 months (range, 0.1-16.6); $86 \%$ of patients were still receiving ibrutinib treatment at the time of analysis. The results of the study disclosed that Ibrutinib significantly improved PFS versus ofatumumab; the median duration of PFS was not reached in the ibrutinib group (with a PFS rate of $88 \%$ at 6 months) compared with a median of 8.1 months in the ofatumumab group (with a PFS rate of $65 \%$ at 6 months) (hazard ratio for progression or death in the ibrutinib group, $0.22 ; \mathrm{p}<0.001$ ). This represents a $78 \%$ reduction in risk of progression or death among patients treated with ibrutinib compared with ofatumumab. The effect of ibrutinib on PFS was robust and observed across all subgroups examined, including patients refractory to chemoimmunotherapy and those with the $17 \mathrm{p} 13.1$ deletion. Thus, Ibrutinib significantly improved the OS rate versus ofatumumab (hazard ratio for death, $0.43 ; \mathrm{p}=0.005$,) with the risk of death reduced by $57 \%$; at 12 months, the OS rate was $90 \%$ in the ibrutinib group and $81 \%$ in the ofatumumab group. The effect of ibrutinib on OS was robust and observed across all subgroups examined. At the time of analysis, 57 patients in the ofatumumab group had crossed over to ibrutinib due to confirmed disease progression. The response rate was higher in the ibrutinib group versus the ofatumumab group (63\% vs $4 \%$ ). $43 \%$ in the ibrutinib group had a PR versus $4 \%$ in the ofatumumab group. ${ }^{59}$

In conclusion, the research over the role of Bruton's agammaglobulinemia tyrosine kinase in B-lymphocyte development, differentiation, signaling and survival has led to better understanding of the pathogenesis of B-cell malignancies. ${ }^{14}$ Down-regulation of BTK activity is an attractive novel strategy for treating patients with B-cell malignancies particularly CLL. ${ }^{56}$ The role of BTK in B-cell signaling, molecular interactions between B-lymphoma cells and neoplastic microenvironment will be translated into clinical trials that would be very helpful for the better management of the patients. ${ }^{13,14,55,57}$ Likewise, the treatment algorithms of B-lymphomas will continue to be revised to a more personalized approach to treat with improved efficacy devoid of unnecessary toxicity. ${ }^{43,58}$

\section{Acknowledgements}

We would like to thank the courtesy of Dr. Johan Aschan, MD, PhD, Assoc. Prof. For the Figures of the manuscript.

\section{REFERENCES}

1. Arita A, McFarland DC, Myklebust JH, et al. Signaling pathways in lymphoma: pathogenesis and therapeutic targets. Future Oncol 9: 1549-1571, 2013. 
2. Robak T, Robak P. BCR Signaling in Chronic Lymphocytic Leukemia and Related Inhibitors Currently in Clinical Studies. Int Rev Immunol 32: 358-376, 2013.

3. Burger JA. Bruton's Tyrosine Kinase (BTK) Inhibitors in Clinical Trials. Curr Hematol Malign Reports 9: 44-49, 2014.

4. Schwarzbich MA, Witzens-Harig M. Ibrutinib. Rec Result Cancer Res 201: 259-267, 2014.

5. Chang BY. Biology of covalent BTK inhibitor PCl-32765 (Ibrutinib): From bench to bedside. Abst Papers Am Chem Soc 245: 250A, 2013.

6. Aalipour A, Advani RH. Bruton tyrosine kinase inhibitors: a promising novel targeted treatment for $\mathrm{B}$ cell lymphomas. $\mathrm{Br}$ J Haematol 163: 436-443, 2013.

7. Wiestner A, Herman S, Mustafa R, et al. Potent single agent activity of Ibrutinib (PCl-32765) in patients with chronic lymphocytic leukemia (CLL): clinical and translational results from an ongoing phase II study. Cancer Res 73: 141A, 2013.

8. Woyach JA, Johnson AJ, Byrd JC. The B-cell receptor signaling pathway as a therapeutic target in CLL. Blood 120: 11751184, 2012.

9. Jain $\mathrm{N}$, O'Brien S. Ibrutinib (PCl-32765) in Chronic Lymphocytic Leukemia. Hematol Oncol Clin North Am 27: 851-860, 2013.

10. Brown JR. Ibrutinib (PCl-32765), the First BTK (Bruton's Tyrosine Kinase) Inhibitor in Clinical Trials. Curr Hematol Malign Rep 8: 1-6, 2013.

11. Farooqui M, Lozier JN, Valdez J, et al. Ibrutinib (PCl 32765) Rapidly Improves Platelet Counts in Chronic Lymphocytic Leukemia/Small Lymphocytic Lymphoma (CLL/SLL) Patients and Has Minimal Effects On Platelet Aggregation. Blood 120: 1789A, 2012.

12. Akinleye A, Furqan M, Adekunle O. Ibrutinib and Indolent B-Cell Lymphomas. Clin Lymphoma Myeloma Leukem DOI: 10.1016/j.clml.2013.11.005, 2014.

13. O'Brien S, Furman RR, Coutre SE, et al. Ibrutinib as initial therapy for elderly patients with chronic lymphocytic leukaemia or small lymphocytic lymphoma: an open-label, multicentre, phase 1b/2 trial. Lancet Oncol 15: 48-58, 2014.

14. Novero A, Ravella PM, Chen Y, Dous G, Liu D. Ibrutinib for B cell malignancies. Exp Hematol Oncol 3: 4-10, 2014.

15. Woyach JA, Bojnik E, Ruppert AS, et al. Bruton's tyrosine kinase (BTK) function is important to the development and expansion of chronic lymphocytic leukemia (CLL). Blood 123: 1207-13, 2014.

16. Burger JA, Buggy JJ. Bruton tyrosine kinase inhibitor ibrutinib (PCl-32765). Leukem Lymphoma 54: 2385-2391, 2013.

17. Niemann CU, Biancotto A, Chang BY, et al. Cytokine and TCell Phenotypic Changes Upon In Vivo Ibrutinib Therapy For CLL - Targeting Both CLL Cells and The Tumor-Microenvironent. Blood 122: 2856A, 2013.

18. Niemann CU, Jones J, Wiestner A. Towards Targeted Therapy of Chronic Lymphocytic Leukemia. In: Malek S, ed. Advances in Chronic Lymphocytic Leukemia 792: 259-291, 2013.

19. Andritsos LA, Jaglowski SM. Ibrutinib Inhibitor of TyrosineProtein Kinase BTK Oncolytic. Drugs Future 38: 359-366, 2013.
20. Niemann CU, Wiestner A. B-cell receptor signaling as a driver of lymphoma development and evolution. Semin Cancer Biol 23: 410-421, 2013.

21. Herman SEM, Mustafa RZ, Martyr SE, et al. Effective Inhibition Of Tumor Microenvironment Interactions In CLL Patients Treated With The BTK Inhibitor Ibrutinib Results In Sustained Inhibition Of Tumor Proliferation and Survival Pathways. Blood 122: 118, 2013.

22. Ponader S, Burger JA. Bruton's Tyrosine Kinase: From XLinked Agammaglobulinemia Toward Targeted Therapy for B-Cell Malignancies. J Clin Oncol 32: 1830-1839, 2014.

23. Herman SE, Mustafa RZ, Gyamfi JA, et al. Ibrutinib inhibits B-cell receptor and NF-kappaB signaling and reduces tumor proliferation in tissue-resident cells of patients with chronic lymphocytic leukemia. Blood DOI:10.1182/ blood-2014-02-548610, 2014.

24. Chang BY, Francesco M, De Rooij MFM, et al. Egress of CD19(+)CD5(+) cells into peripheral blood following treatment with the Bruton tyrosine kinase inhibitor ibrutinib in mantle cell lymphoma patients. Blood 122: 2412-2424, 2013.

25. Herman SEM, Mustafa RZ, Gyamfi JA, et al. Ibrutinib inhibits $\mathrm{BCR}$ and NF-KB signaling and reduces tumor proliferation in tissue-resident cells of patients with CLL. Blood 123: 32863295, 2014.

26. Cheng S, Ma J, Guo A, et al. BTK inhibition targets in vivo CLL proliferation through its effects on B-cell receptor signaling activity. Leukemia 28: 649-657, 2014.

27. Han T, Fan L, Li JY, Xu W. Role of chemokines and their receptors in chronic lymphocytic leukemia Function in microenvironment and targeted therapy. Cancer Biol Therapy 15: 3-9, 2014.

28. Coelho V, Krysov S, Steele A, et al. Identification in CLL of circulating intraclonal subgroups with varying B-cell receptor expression and function. Blood 122: 2664-2672, 2013.

29. Herman SEM, Jones J, Mustafa RZ, et al. In Vivo effects of ibrutinib on the migration of chronic lymphocytic leukemia cells differ between patients and reduce the ability of the bone marrow microenvironment to attract the tumor cells. Blood 122: 604A, 2013.

30. Sehgal L, Mathur R, Braun FK, et al. FAS-antisense 1 IncRNA and production of soluble versus membrane Fas in B-cell lymphoma. Leukemia DOI: 10.1038/leu.2014.126, 2014.

31. Wodarz D, Garg N, Komarova NL, et al. Kinetics of chronic lymphocytic leukemia (CLL) cells in tissues and blood during therapy with the BTK inhibitor ibrutinib. Blood 123: 41324135, 2014.

32. Rossi D, Gaidano G. Lymphocytosis and ibrutinib treatment of CLL. Blood 123: 1772-1774, 2014.

33. Mustafa RZ, Herman SEM, Jones J, et al. Ibrutinib inhibits B-cell adhesion and causes an efflux of chronic lymphocytic leukemia cells from the tissue microenvironment into the blood leading to a transient treatment-induced lymphocytosis. Blood 122: 674A, 2013.

34. Herman SE, Niemann CU, Farooqui M, et al. Ibrutinib-induced lymphocytosis in patients with chronic lymphocytic leukemia: correlative analyses from a phase II study. Leukemia DOI: 10.1038/leu.2014.122, 2014. 
35. Benekli M, Buyukasik Y, Haznedaroglu IC, et al. Chronic lymphocytic leukemia presenting as acute urinary retention due to leukemic infiltration of the prostate. Annals Hematol 73: 143-144, 1996.

36. Hayran M, Koca E, Haznedaroglu IC, et al. Predicting chronic leukaemias from assessment of complete peripheral blood counts. J Int Med Res 34: 640-7, 2006.

37. Hutchinson CV, Dyer MJ. Breaking good: the inexorable rise of BTK inhibitors in the treatment of chronic lymphocytic leukaemia. Br J Haematol DOI: 10.1111/bjh.12895, 2014.

38. Rushworth SA, Bowles KM, Barrera LN, et al. BTK inhibitor ibrutinib is cytotoxic to myeloma and potently enhances bortezomib and lenalidomide activities through NF-kappa B. Cellular Signalling 25: 106-112, 2013.

39. Damle RN, Temburni S, Aggarwal P, et al. Changes in immune cell populations in relapsed/refractory CLL patients treated with a Bruton's Tyrosine Kinase (BTK) Inhibitor, Ibrutinib (PCl-32765), in combination with Bendamustine and Rituximab (BR). Cancer Res 73: 3531A, 2013.

40. Molica S. The emerging role of ibrutinib in the treatment of chronic lymphocytic leukemia. Expert Rev Hematol 6: 543-6, 2013.

41. Brown JR, Barrientos JC, Barr PM, et al. Ibrutinib In Combination With Bendamustine and Rituximab Is Active and Tolerable In Patients With Relapsed/Refractory CLL/SLL: Final Results Of a Phase 1b Study. Blood 122: 525A, 2013.

42. Burger JA, Keating MJ, Wierda WG, et al. Ibrutinib In Combination With Rituximab (iR) Is Well Tolerated and Induces a High Rate Of Durable Remissions In Patients With High-Risk Chronic Lymphocytic Leukemia (CLL): New Updated Results of a Phase II Trial In 40 Patients. Blood 122: 675A, 2013.

43. Kharfan-Dabaja MA, Wierda WG, Cooper LJN. Immunotherapy for chronic lymphocytic leukemia in the era of BTK inhibitors. Leukemia 28: 507-517, 2014.

44. Blum KA, Christian B, Flynn JM, et al. A Phase I Trial of the Bruton's Tyrosine Kinase (BTK) Inhibitor, Ibrutinib (PCl32765), in Combination with Rituximab (R) and Bendamustine in Patients with Relapsed/Refractory Non-Hodgkin's Lymphoma (NHL). Blood 120: 1643A, 2012.

45. O'Brien SM, Barrientos JC, lan W. Flinn, et al. Combination of the Bruton's tyrosine kinase (BTK) inhibitor PCl-32765 with bendamustine $(\mathrm{B})$ /rituximab $(\mathrm{R})(\mathrm{BR})$ in patients $(\mathrm{pts})$ with relapsed/refractory (R/R) chronic lymphocytic leukemia (CLL): Interim results of a phase Ib/ll study. J Clin Oncol 30: 6515A, 2012.

46. Kohrt HE, Sagiv-Barfi I, Rafia S, et al. Ibrutinib antagonizes rituximab-dependent NK cell-mediated cytotoxicity. Blood 123: 1957-1960, 2014

47. Byrd JC, Furman RR, Coutre S, et al. The Bruton's Tyrosine Kinase (BTK) Inhibitor Ibrutinib (PCl-32765) Promotes High Response Rate, Durable Remissions, and Is Tolerable in Treatment Naive (TN) and Relapsed or Refractory (RR) Chronic Lymphocytic Leukemia (CLL) or Small Lymphocytic Lymphoma (SLL) Patients Including Patients with High-Risk $(\mathrm{HR})$ Disease: New and Updated Results of 116 Patients in a Phase lb/ll Study. Blood 120: 189A, 2012.

48. Fowler NH, Advani RH, Sharman J, et al. The Bruton's Tyrosine Kinase Inhibitor Ibrutinib (PCl-32765) Is Active and Tol- erated in Relapsed Follicular Lymphoma. Blood 120: 156A, 2012.

49. Cinar M, Hamedani F, Mo ZC, et al. Bruton tyrosine kinase is commonly overexpressed in mantle cell lymphoma and its attenuation by Ibrutinib induces apoptosis. Leukemia Res 37: 1271-1277, 2013.

50. Zoellner AK, Dietzfelbinger R, Hutter G, et al. The CDK 4/CDK 6 Inhibitor PD0332991 significantly reduces cell growth via a G1 phase arrest in Mantle Cell Lymphoma cell lines and additively increases effects of Ibrutinib. Onkologie 36: 198A, 2013.

51. Wang ML, Rule S, Martin P, et al. Targeting BTK with Ibrutinib in Relapsed or Refractory Mantle-Cell Lymphoma. New Engl J Med 369: 507-516, 2013.

52. Cameron F, Sanford M. Ibrutinib: First Global Approval. Drugs 74: 263-71, 2014

53. Sivina M, Kreitman RJ, Arons E, et al. The bruton tyrosine kinase inhibitor ibrutinib (PCl-32765) blocks hairy cell leukaemia survival, proliferation and $\mathrm{B}$ cell receptor signalling: a new therapeutic approach. Br J Haematol DOI: 10.1111/ bjh.12867, 2014.

54. Advani RH, Buggy JJ, Sharman JP, et al. Bruton Tyrosine Kinase Inhibitor Ibrutinib (PCl-32765) Has Significant Activity in Patients With Relapsed/Refractory B-Cell Malignancies. J Clin Oncol 31: 88-94, 2013.

55. Maddocks K, Blum KA. Ibrutinib in B-cell Lymphomas. Curr Treatment Option Oncol 15: 226-237, 2014.

56. Awan FT. Ibrutinib: targeting the hidden CLL. Blood 123: 3215-3216, 2014

57. Brown JR. Ibrutinib in chronic lymphocytic leukemia and B cell malignancies. Leukemia Lymphoma 55: 263-269, 2014.

58. Rai KR, Barrientos JC. Movement toward Optimization of CLL Therapy. New Engl J Med 370: 1160-2, 2014.

59. Byrd JC Brown, JR, O'Brien S, et al. Ibrutinib Versus Ofatumumab in Previously Treated Chronic Lymphoid Leukemia N Engl J Med. DOI: 10.1056/NEJMoa1400376, 2014.

\section{Correspondence}

Dr. İbrahim C. HAZNEDAROĞLU

Hacettepe Üniversitesi Tıp Fakültesi

İç Hastalıkları Anabilim Dalı

Hematoloji Bilim Dall,

Sinhiye, ANKARA / TURKEY

Tel: (+90.312) 3051543

Fax: (+90.312) 3051614

e-mail: ichaznedaroglu@gmail.com 